\title{
THE PERILS OF VACCINE HESITANCY BASED ON CONSPIRACY THEORIES AND MISINFORMATION: IMPLICATIONS AND WAY FORWARD FOR PAKISTAN
}

\author{
Naeem Mubaraka ${ }^{a}$ Asad Majeed Khan ${ }^{\text {, Sundus Tariq }}{ }^{b}$, Sabba Kanwala ${ }^{a}$ Saba Tariq ${ }^{\mathrm{b}}$ \\ aLahore Medical \& Dental College, University of Health Sciences, Lahore, Punjab, Pakistan. \\ bUniversity Medical and Dental College, The University of Faisalabad, Pakistan.
}

KEYWORDS: Vaccine hesitancy, Conspiracy theories, Misinformation, COVID-19 pandemic, Social media, Pakistan, Asia.

BACKGROUND: Around the world, COVID-19 pandemic has exposed vulnerabilities of healthcare systems and whipped out years of progress on poverty alleviation. Nevertheless, the development of multiple COVID-19 vaccines in such a short span of time is truly a triumph of science. World Health Organization (WHO) grades vaccination as "one of the most cost-effective public health interventions to date"[1]. Vaccines work in two distinct ways i.e., directly protecting the one who receives and indirectly, as the vaccinated people could not infect others subsequently. In this way a vaccine reduces the number of hospital admissions and deaths. How swiftly would this combined effect appear at a population level is determined by the duration and the scale of vaccination efforts. To achieve a population level effect of COVID-19 vaccine in a country; different approaches to vaccinate masses are under huge discussion to decide the priority population i.e., who will receive the jab first. From a youth first approach as in Indonesia to textured approaches, as in Pakistan, that prioritize the vulnerable or exposed populations i.e., elderly and healthcare professionals respectively[2].

doi: https://doi.org/10.37723/jumdc.v12i2.624

\section{How to cite this:}

Mubarak N, Khan AM, Tariq S, Kanwal S, Tariq S. THE PERILS OF VACCINE HESITANCY BASED ON CONSPIRACY THEORIES AND MISINFORMATION: IMPLICATIONS AND WAY FORWARD FOR PAKISTAN. jumdc. $2021 ; 12(2)$ : vii-xiv

doi: https://doi.org/10.37723/jumdc.v12i2.624

This is an Open Access article distributed under the terms of the Creative Commons Attribution License (http://creativecommons.org/licenses/by/4.0), which permits unrestricted use, distribution, and reproduction in any medium provided the original work is properly cited. 


\section{INTRODUCTION:}

\section{Vaccine hesitancy based on misinformation, disinformation and conspiracy theories:}

As the marathon of COVID-19 vaccination drive has begun, countries are scrambling to procure and administer vaccines, however, getting enough people vaccinated would remain a serious challenge. It is actually the belief or attitude about the vaccine that builds tendency to accept or reject the vaccine. Attitude and beliefs of public are largely influenced on the basis of prevalent information and to the extent a given society seeks and trusts scientific knowledge [3,4]. Misinformation is "misleading information created or disseminated without manipulative or malicious intent" e.g., "the use of onions can cure COVID-19". On the other hand, "disinformation" involves a deliberate dissemination of confusion or misinformation for economic or political reasons, or simply to disrupt public communication processes, for example, COVID-19 virus was made in a Chinese lab and spread across the globe as part of Chinese or Russian great game to knock down US economy. Lastly, the conspiracy theories are subtype of mis-disinformation based on rumours or fiction and generally sooth or favour a popular or preconceived narrative in a given society ${ }^{[5,6]}$. Conspiracy theories aligned with a religious or political conviction receive farranging acceptance in societies with pervasive wishful thinking. For instance, "Vaccine is a part of grand Zionist plan to make Muslims infertile". Mis-disinformation and conspiracy theories have always been a part of human race, however, in the post truth era, it has altogether different dynamics. COVID-19 is the first pandemic in which social media (Facebook, WhatsApp, Instagram, Twitter, YouTube etc.) is playing a pivotal role in the dissemination of information. Nowadays, social media replicates waves of misinformation faster than a virus as a result misinformation travels unbridled across this global village. During this pandemic, social media was brimmed with misinformation, disinformation and conspiracy theories about COVID-19 vaccine and the virus. These conspiracy theories have made significant number of people reluctant and sceptic to receive the vaccine (despite its availability), leading to the widespread social phenomenon of "vaccine hesitancy".
Corresponding Author:

Naeem Mubarak

Lahore Medical \& Dental College, University

of Health Sciences,

Email: naeem.mubarak@Imdc.edu.pk
These foes of vaccines could profoundly undermine the efforts taken to contain the pandemic. WHO enlists "vaccine hesitancy" as a top threat to efforts to contain the virus/ pandemic ${ }^{[7]}$.

Vaccine hesitancy exists in almost all societies. Jonathan Berman, the author of "Anti-vaxxers: How to Challenge a Misinformed Movement" has discussed the history of anti-vaxxers in Western societies which are mainly vaccine hesitant due to safety concerns ${ }^{[8]}$. On the other hand, the Orientalist societies are vaccine hesitant more because of the underlying conspiracy theories and misinformation. For instance, recently an Iranian cleric urged public not to get COVID-19 vaccine as it could possibly make people homosexual [9]. Similarly, in Malaysia and Indonesia, public raised a great hue and cry against COVID-19 vaccination drive based on a piece of misinformation that "the vaccine is Haram as it contains pork gelatin"[10]. In line with this, Islamic clerics in UAE and India passed a religious decree against COVID-19 vaccine that adversely affected the uptake of the vaccine in the Muslim communities.

\section{VACCINE HESITANCY AND PAKISTAN:}

Pakistan has a bitter history of vaccine hesitancy based on conspiracy theories. Pakistan initiated polio vaccination drive in 1994 , however, failed to achieve the status of a polio-free state till date. Polio vaccination suffered severe backlashes because of the beliefs based on a conspiracy theory that the vaccine was a part of Zionist grand plan to make Muslim population infertile/ 
impotent. Today, Pakistan stands as the 5th most populous country in the world; and one of the two countries (the other is Afghanistan) where active polio cases are still present [11,12]. In Pakistan, the anti-polio-vaccine sentiment reaches to that intensity where government deploys police to protect vaccinators during the vaccination campaign every year. Despite the security arrangements, many vaccinators and police officials were gunned down in a series of attacks. Thus, misinformation and conspiracy theories not only increase the financial burden of a given vaccination program for a country but also cost lives.

In Pakistan, fight against COVID-19 pandemic was two-fold i.e., to contain the virus, and to curb the ignorance. The National Command Operation Center (NCOC) has taken appreciable steps in containment of the virus, however, on ground no stern measures were adopted to counter the growing surge of the conspiracy theories and misinformation. Nevertheless, fighting with this infodemic of misinformation was equally important. Misinformation and conspiracy theories were widely shared against COVID-19 vaccine on the social media handles in Pakistan. For instance, it was propagated that Bill Gates planned to insert a nano chip in human through a global vaccination program (as of COVID-19 vaccine), to make a global surveillance system ${ }^{[13,14]}$. Similarly, a conspiracy theory revolved around the point that AstraZeneca vaccine is made in India (a country perceived as a traditional rival) and hence, Indian made vaccine might have some harmful ingredient. The damage of misinformation gets amplified when an influential person or celebrity, such as a political or religious leader spread these words as they have a huge fan following. For instance, a widespread conspiracy theory in Pakistan twirled on the supposition that Covid-19 vaccine will promote incest and make Muslim nations obey the new world order.

The pertinent question is who gave them airtime, present them as analysist and invite them in educational institutes. This infodemic of misinformation and conspiracy theories makes the crisis in a pandemic even worst by creating an environment of uncertainty that suits the spread of misinformation. Pakistani society is quite vulnerable to such conspiracy theories. Currently, there exists a quite vocal antiCOVID-19 vaccine moment in Pakistan featuring religious and political leaders ${ }^{[15] .}$

Hope in the vial of COVID-19 vaccine has arrived in Pakistan and government has started vaccinating frontline healthcare workers and elderly since 2nd Feb. 2021. However, as compared to all its neighbours, the pace of vaccination is too low in Pakistan i.e., only a few lacs have been vaccinated. Common people aside, even the well-educated people are hesitant to receive the vaccine primarily due to misinformation and conspiracy theories.

\section{WHY DO WE READILY BELIEVE MISINFORMATION AND CONSPIRACY} THEORIES?

Why is Pakistani society so riddled with conspiracy theories and vaccine scepticism? Why do we exhibit immense readiness to believe misinformation or conspiracy theories? What is the origin of anti-vaccine sentiment in the credulous society of Pakistan? A two-word answer to these questions could be "wishful thinking".

In addition to the vulnerabilities, COVID-19 pandemic has also exposed the ways different societies acquire knowledge and process information i.e., emotionally or logically. This is in line with the theory of planned behaviour that differentiates two aspects of attitude i.e., affective attitude (elicited by emotions) and cognitive attitude (evoked by rational evaluations) ${ }^{[4,16]}$. On one hand, societies with a scientific mindset ask for scientific evidence whenever a piece of information is presented. People in these societies take scientific knowledge seriously and heavily rely on scientific data to make decisions. "Scientism" (belief that scientific method can find truth or objective reality) is generally well advocated in these societies because people know that scientific knowledge is acquired through a set of procedures to reach an evidence that is free from different biases. Here, people understand that unlike a fixed religious dogma, 
scientific evidence can be replaced with more convincing dataand the process is continuous ${ }^{[8]}$. Furthermore, appreciation of the voice of dissent is another trait in these societies. Take an example of $\mathrm{Dr} \mathrm{Li}$ Wenliang who forewarned chinses authorities for the very first time about the "Pneumonia of an unknown cause" spreading rapidly in patients in Wuhan central hospital. He was initially summoned and admonished to be involved in anti-state propaganda, however, he kept on writing in his personal blog to alarm people and the government. He later died of COVID-19, however, based on his red flags, China was successful in launching a response that was systematic and well-coordinated to flatten the curve based on the scientific principles of Epidemiology. Now he has emerged as a national hero who epitomizes the importance of "voice of dissent", especially based on the transparency and audacity to report scientific facts, and received more respect and attention than simple agreements in a rationalist society ${ }^{[17]}$.

On the other hand, societies filled with wishful beliefs have a distorted view of the science and scientific method. In these societies, opinions are built on whims and vibes, backed by preconceived beliefs and generally follow the popular narratives without questioning or asking for a scientific evidence. Psychologically, accepting a piece of information without asking a question indicates a feeble mind. The narratives hold by these societies are generally based on the axiom of "I believe, so it is true" and people generally discourage voices of dissent. Here, people get uncomfortable and vehemently resist an evidence (no matter how valid and strong) that is against their preconceived beliefs, a phenomenon referred in psychology as "cognitive dissonance"[16]. In these societies anecdote often wins over scientific facts and people are fond of yellow journalism and hyperbole. In these societies, people do not question the narratives imposed on them.

They press the "share" tab as soon as any information flashes out on the social media and it is aligned with the perception they hold. This sharing of unconfirmed information could also be an attempt to pose superior in knowledge or people's tendency to believe on the convenient things or flow with the popular or dominant narrative or trend ${ }^{[16]}$.

The latter is the case of Pakistani society that generally appreciates loud oratory based on stock rhetoric that appeals to religious or political beliefs and emotions. For instance, majority of population has a preconceived notion that Jews plan against Muslims, as the vaccine is made by Jews, hence, vaccine would have something dangerous for them. Misinformation and conspiracy theories if match with those beliefs poured in the mind since childhood, receive immediate acceptance [11,13]. Pakistani society has never been trained to evaluate a piece of information scientifically or logically. In Pakistan, the dilemma is; misinformation is not merely propagated by the religious or uneducated people, many highly qualified people can be cited. Now when common people hear a highly educated people spreading misinformation, they would take it as an authentic piece of information. While, it is a typical example of "bounded rationality" a phenomenon in which a person thinks judiciously only in a limited circle but out of that circle same person comes up with irrational statements and decisions ${ }^{[16]}$. For instance, a professor of medicine or a pulmonologist, is an expert in deciding the medicines used for COVID-19 patients, however, when shares a narrative openly that a vaccine from India would have something harmful or "I will wait for Russian or Pfizer vaccine to arrive" appears unexpected and sounds irrational. It is like, someone offers a drowning man a life jacket, but he refuses by saying "I will wait for a superior brand of life jacket".

Thus, the problem is mindset, the person has not studied medical science as science, but just to obtain a degree like any other degree to get settled in life. It is also pertinent to mention here that all vaccines pass through same phases of clinical trials. The misinformation that Chinese vaccine is just $50 \%$ effective is again a half truth. Bloomberg dug the details and responded that efficacy of any vaccine is reported for all range of symptoms. Sinovac's efficacy is $50 \%$ for mild symptoms, however, for moderate symptoms that require medical intervention, the efficacy 
is about $84 \%$ and for moderate-to-severe Covid cases, it's $100 \%{ }^{[18]}$. In plain language the efficacy for severe symptoms is still quite high.

Correlating with our argument, many highly qualified individuals even with PhDs from technological advance countries share these conspiracy theories. This proves that consuming latest technology or cramming scientific facts is altogether different from having a scientific mindset. For instance, a lab technician may have an extraordinary skill to extract RNA or DNA and perform different experiments but do not believe evolution. Thus, the person has not developed a scientific mindset that involved analytical reasoning and creativity. Take another analogy, a USB device can store tera-byte of data, however, a CPU would remain superior in terms of its ability to process the data in a computer. Similarly, a traditional mindset may memorise heaps of data and occasional apply, however, may never modify or transform it.

The root cause of this gross incompetency (lack of logical and rational thinking) is embedded in the way students are being taught in academic institutes. In Pakistan, generally students are not trained or appreciated to ask questions when presented with a piece of information. Asking a question constitutes disrespect. The system of education needs an overhaul to inculcate logical and rational thinking in the young mind [14].

\section{SOLUTION; WAY FORWARD:}

Conspiracy theories and misinformation spread more rapidly when access to trustworthy information is limited. For a social media user, information on social media is like standing in a hall of mirrors where it is difficult to differentiate the truth from falsity. WHO Resolution (WHA73.1) urges all member states to take actions to counter mis- and disinformation in this highly digitalized world and promote timely dissemination of science backed evidence-based information to the public ${ }^{[19]}$. Hence, combating misinformation and conspiracy theories should be a crucial part of current or any future pandemic preparedness. In this context, we propose an outline of a working model based on a multiprong strategy that includes:

1. A provincial level fact-check social media page/channel/handle moderated by the respective government may be established which would publish and distribute valuable and authentic information in local language. This information should be findable, searchable and shareable. This page would serve as a trustworthy source of information for public and first point of contact to confirm any information. This should be followed by a large-scale awareness campaign to guide public where to look for a trust worthy piece of information on internet/social media. These social media channels/handles can be used to combat misinformation and conspiracy theories through a counter narrative approach.

2. Ensuring online presence of concerned experts will be immensely helpful. In context of public health, social media is powerful, yet underutilized source. It can play a vital role in pandemic preparedness, response and recovery. There is an urgent need of physicians, public health experts, researchers and other healthcare professional to make sure their presence online i.e., on social media. They can easily build a loyal community of their followers ${ }^{[20]}$. An online community of the concerned experts can tag up with the provincial fact-check social media handle to further assist the spread of a counter narrative to refute any false claim or a conspiracy theory.

3. Provincial governments may devise a mechanism of surveillance of social media data and partner with trusted sources to prevent dissemination of any misinformation. There is a pressing need to devise computational methods to recognise and curb the emerging patterns of misinformation. Furthermore, a government body should be working on "find and replace" approach to counter the spread of misinformation ${ }^{[21]}$. The surveillance of data on the social media may also help to identify adherence patterns or attitude of the public for healthcare interventions and also gave an idea where to target the deficiencies. 
4. A ban on the rumour mongers or known conspiracy theorist for public appearances should be imposed. Although freedom of speech is a basic human right conferred by the constitution under international obligations, however, "fulminating harangue" or shouting "fire" in a crowded theatre cannot be justified on the name of freedom of speech. Hence, if a person is known to spread misinformation and conspiracy theories on mass media either he should be banned or always be invited on a debate where both opinions are presented to the viewers.

5. All academic institutes should build social media cells which propagate the evidencebased narratives. Two examples can be cited the Aga Khan University, Karachi and The University of Faisalabad where similar material was published online throughout the pandemic in Urdu (national language of Pakistan).

6. To address the root cause of this problem, encouragement of young minds to ask questions in classes. Promoting a culture of critical and logical thinking in educational institutions and in the society would be the key to curtail the menace of wishful thinking. More specifically, every institution must offer some diploma or short courses on logical and critical thinking in addition to the curriculum irrespective of the discipline.

7. A point of view regarding the dilution of the religious factor could be possible by engaging religious leaders in the vaccination drive to influence the community of the followers. Hashmi et al proposed a collaborative working model to train the trainer (train the religious leaders) ${ }^{[22]}$. Apparently, it looks logical that various people work together to bring a social or behavioural change. However, we argue that the model may not be sustainable in the long run. There is a notable flaw in the assumption underlying this model and that is at the root of this problem i.e., the difference between a religious mindset and a scientific mindset i.e., the inherent anti-science nature of religious leaders/dogmas and their followers. Theory of reasoned action also implies that collaboration would be successful only if viewed useful by all the stakeholders. Religious scholars have been trained absolutely in a different way throughout life to propagate and preach the spiritual or parascience or meta-physical events by the art of effective oratory, that is highly applauded by their followers. Furthermore, we feel more aligned to a prudent model that engages the enlightened religious scholars to engage in vaccine campaign as a part of multiprong strategy ${ }^{[15]}$. Alternatively, we propose a collaborative model between policy makers and community influencers, such as teachers, motivational speakers, writers, newspaper columnists and showbiz personalities.

8. Focus specially on the PhD faculty of the universities or colleges to train the teachers in all educational institutes to promote logical and critical thinking to bring a social and behavioural change. Nevertheless, the PhD faculty itself is required to come up with a clear scientific mindset.

\section{CONCLUSION:}

Ultimately scientific methods will save the human race; however, the case of Pakistan is of pressing concerns. After the experience of polio vaccine, Pakistan cannot afford another massive resistance against COVID-19 vaccine based on conspiracy theories. The current surge in misinformation and conspiracy theories about COVID-19 vaccine could impede the way out of this pandemic for Pakistan. There is a dire need to train public where to look up for an authentic piece of information. More emphasis should be on the root cause that is the mindset than on the social media posts. The antidot to misinformation is critical and logical thinking that involves careful inspection of the information and understanding all the possible biases. Cognitively empower people to the extent whenever they are at a crossroad, they can decide how to find the truth scientifically. The current dilemma requires to reach and persuade the sceptics or haters of vaccine through a counter 
narrative advocated by teachers, motivational speakers, writers, celebrities and TV anchors under a collaborative working model. We all share the common responsibility to combat the antivaccination activism that is closely tied with gross misinformation and conspiracy theories. We urge stakeholders to adopt a pre-emptive approach to combat mis-disinformation and establish preparedness of healthcare work force. Let's be a part of the campaign, think twice before sharing social media posts especially related to healthcare issues. If a permanent solution is not devised at the moment, the conspiracy theories and its adverse effect on vaccine uptake will continue unabated and the repercussions would be unimaginable in terms of resurges and international pressure.

ACKNOWLEDGEMENT: None.

CONFLICT OF INTEREST: All authors disclose no conflict of interest.

\section{GRANT SUPPORT \& FINANCIAL DISCLOSURE: None}

\section{REFERENCES:}

1. WHO. Global Vaccine Action Plan Monitoring, Evaluation \& Accountability. 2013; 31, World Health Organization.

2. Nnadi C, Etsano A, Uba B, Ohuabunwo C, Melton M, Wa Nganda G, et al. Approaches to vaccination among populations in areas of conflict. The Journal of Infectious Diseases. 2017;216(suppl_1):S368-3672.

3. Fischer $R$, Boer $D$. Motivational basis of Personality traits: A meta-analysis of value-personality correlations. Journal of personality. 2015;83(5):491-510.

4. Ponizovskiy V, Grigoryan L, Kühnen U, Boehnke $\mathrm{K}$. Social construction of the value-behavior relation. Frontiers in Psychology. 2019; 10:934. Doi:10.3389/fpsyg.2019.00934

5. Bruns A, Harrington S, Hurcombe E. <? covid19?>'Corona? 5G? or both?': The dynamics of COVID-19/5G conspiracy theories on Facebook. Media International Australia. 2020;177(1):12-29.
6. Romer D, Jamieson $\mathrm{KH}$. Conspiracy theories as barriers to controlling the spread of COVID-19 in the US. Social Science \& Medicine. 2020; 263:113356.

7. Xiao X, Wong RM. Vaccine hesitancy and perceived behavioral control: A Metaanalysis. Vaccine. 2020;38(33):5131-5138.

8. Berman JM. Anti-vaxxers: How to challenge a misinformed movement. One Rogers Street Cambridge, MA 02142-120: The MIT Press; 2020.

9. Merrifield R. Iranian cleric bizarrely warns people against Covid vaccine saying it "makes you gay" - World News - Mirror Online; 2021 feb 09 [cited 2021 May 05 ]. Available from: https://www.newsbreak. com/news/2160622953143/iranian-clericbizarrely-warns-people-against-covidvaccine-saying-it-makes-you-gay.

10. Khoo YSK, Ghani AA, Navamukundan AA, Jahis $R$, Gamil A. Unique product quality considerations in vaccine development, registration and new program implementation in Malaysia. Hum Vaccines Immunother. 2020;16(3):530-538.

11. Ali M, Ahmad N, Khan H, Ali S, Akbar F, Hussain Z. Polio vaccination controversy in Pakistan. The Lancet. 2019;394(10202):915-916.

12. Kanwal S, Hussain A, Mannan S, Perveen S. Regression in polio eradication in pakistan: A national tragedy. Vol. 66, Journal of the Pakistan Medical Association. Pakistan Medical Association; 2016: 328-333.

13. Mubarak N. Corona and clergy - The missing link for effective social distancing in Pakistan: Time for some unpopular decisions. International Journal of Infectious Diseases. 2020;95:431-432.

14. Shoukata A, Jafarb M. Scarce Resources and Careless Citizenry: Effects of COVID-19 in Pakistan. 2020;9:214-229.

15. Khan $\mathrm{YH}$, Mallhi $\mathrm{TH}$, Alotaibi NH, Alzarea AI, Alanazi AS, Tanveer N, et al. Threat of COVID-19 vaccine hesitancy in Pakistan: the need for measures to neutralize misleading narratives. The American journal of tropical Medicine and Hygiene. 2020;103(2):603604.

16. Forgas JP, Baumeister R, editors. The Social 
Psychology of Gullibility: Conspiracy Theories, Fake News and Irrational Beliefs. Routledge; 2019: 352.

17. Forman R, Atun R, McKee M, Mossialos E. 12 Lessons learned from the management of the coronavirus pandemic. Health Policy. 2020; 124(6): 577-580. Doi:10.1016/j. healthpol.2020.05.008

18. Bloomberg. Are China' 's Covid Shots Less Effective? Experts Size Up Sinovac. Bloomberg News; 2021 April 13 [cited 2021 May 09] Available from: https://www. bloomberg.com/news/articles/2021-04-13/ are-china-s-covid-shots-less-effectiveexperts-size-up-sinovac.

19. World Health Organization. Managing the COVID-19 infodemic: Promoting healthy behaviours and mitigating the harm from misinformation and disinformation; 2020 Sep [cited 2021 May 09]. Available from: https://www.who.int/news/item/23-092020-managing-the-covid-19-infodemicpromoting-healthy-behaviours-andmitigating-the-harm-from-misinformationand-disinformation.
20. Abbasi J. COVID-19 conspiracies and beyond: how physicians can deal with patients' misinformation. Journal of the American Medical Association. 2021;325(3):208-210.

21. Shahsavari $S$, Holur $P$, Tangherlini TR, Roychowdhury V. Conspiracy in the time of corona: Automatic detection of covid-19 conspiracy theories in social media and the news. ArXiv Preprint ArXiv:2004.13783. 2020.

22. Hashmi FK, Iqbal Q, Haque N, Saleem F. Religious cliché and stigma: A brief response to overlooked barriers in COVID-19 management. Journal of Religion and Health. 2020;59(6):2697-700. 